Supporting Information

\title{
Electrochemically modulated liquid chromatography (EMLC) in fused silica capillary columns*
}

\author{
Robert J. Soto ${ }^{1}$, Mark A. Hayes ${ }^{3}$, and Marc D. Porter ${ }^{2, *}$ \\ ${ }^{1}$ Nano Institute of Utah, and ${ }^{2}$ Departments of Chemistry and Chemical Engineering, The \\ University of Utah, Salt Lake City, Utah, United States of America, 84112 \\ ${ }^{3}$ School of Molecular Sciences, Arizona State University, Tempe, Arizona, United States of \\ America \\ *E-mail: marc.porter@utah.edu
}

Table of Contents

SI-1. Materials and Reagents SI-1

SI-2. Chromatographic System..................................................................................SI-2

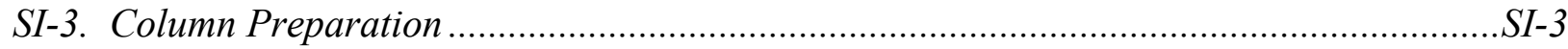

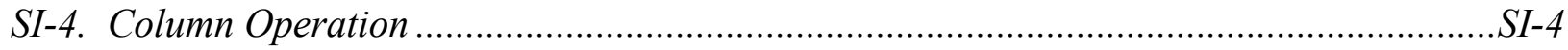

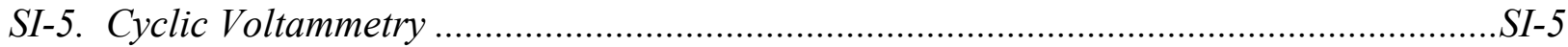

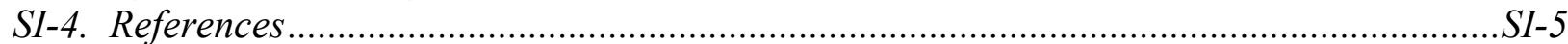

\section{SI-1. Materials and Reagents}

Polyimide-coated fused silica tubing [360 $\mu \mathrm{m}$ outer diameter (OD), 100 or $250 \mu \mathrm{m}$ inner diameter (ID)] was from Polymicro Technologies (Phoenix, AZ). Lithium perchlorate was from Alfa Aesar (Haverhill, MA). Lithium chloride, formamide (99.5\%), and Hypercarb PGC particles with a nominal diameter of $5 \mu \mathrm{m}$ were from ThermoFisher Scientific (Waltham, MA). Acetonitrile (ACN;>99.9\%, HPLC grade), 3-amino-4-hydroxybenzenesulfonic acid (AHBS), 1,2-benzenedisulfonic acid (BDS) dipotassium salt, dibromomethane $\left(\mathrm{CH}_{2} \mathrm{Br}_{2} ; 99 \%\right), 1,3,(6,7)$ naphthalenetrisulfonic acid trisodium salt hydrate (NTS-1 and NTS-2, respectively), and $p$ toluenesulfonic acid (PTS) were from Millipore-Sigma (Burlington, MA). KASIL-1 potassium silicate solution was provided by PQ Corporation (Valley Forge, PA). Perfluoro(alkoxy) alkane (PFA) polymer-coated tungsten wire was from A-M Systems (Sequim, WA). Sodium benzenesulfonate (BS) and 1,5-naphthalenedisulfonic acid (NDS) disodium salt dihydrate were 
from Fluka (Morris Plains, NJ). Water was purified to resistivity of $\mathrm{M} \Omega$-cm using a Barnstead Nanopure water purification system (ThermoFisher Scientific). The aqueous portion of the mobile phase was vacuum filtered through a $0.2 \mu \mathrm{m}$ Nylon filter membrane prior to use.

\section{SI-2. Chromatographic System}

Following the column packing procedure, the column was connected to the chromatographic system (Agilent 1200 series instrument) and flushed with mobile phase at $\sim 120$ bar for several hours until a stable background was observed. The chromatographic system was equipped with a 6-port injection valve ( $90 \mathrm{~nL}$ loop prepared from $50 \mu \mathrm{m}$ ID polymer tubing) and a $500 \mathrm{~nL}$ flow cell for detection by UV-Vis absorbance measurements. Full absorbance spectra were collected for every data point (at a typical sampling frequency of $1 \mathrm{~Hz}$ ), which aided in peak identification based on characteristic absorption bands for each analyte. Unless otherwise specified, all chromatograms were generated based on absorbance at $\lambda=220 \mathrm{~nm}$ on the diode

array detector. The LC system was modified to accommodate the low capillary LC flow rates by including a precolumn flow splitter. The flow splitter was also used to house the pseudoreference electrode (PRE). A schematic of the modified LC system and the placement of the PRE is presented in Figure 2. This construction, detailed in the paragraph below, was developed to (1) place the PRE in close proximity to the PGC stationary phase, thereby minimizing the uncompensated resistance in the electrochemical cell; (2) withstand pressures of up to 400 bar operative in the LC experiments; and (3) prevent the mobile phase from contacting wire leads used to make electrical contact with the PRE.

As a starting point, one end of a $10 \mathrm{~cm}$ long, $0.4 \mathrm{~mm}$ diameter chloridized silver wire ( $\mathrm{Ag} \mid \mathrm{AgCl})$ was soldered to a $\sim 50 \mu \mathrm{m}$ diameter tungsten wire, which served as the electrode lead. 
The solder junction was then inserted into a $\sim 5 \mathrm{~cm}$ piece of $1 \mathrm{~mm}$ ID polyether ether ketone (PEEK) tubing. To seal the solder junction, the internal volume of the PEEK tubing was filled with epoxy and cured at $140^{\circ} \mathrm{C}$ for 2 hours. The PEEK tubing was connected to one free thread of a PEEK tee-union with the $\mathrm{Ag} \mid \mathrm{AgCl}$ inserted through the thru-hole of the tee-union. The remaining length of the $\mathrm{Ag} \mid \mathrm{AgCl}$ wire $(\sim 7 \mathrm{~cm})$ that protruded from the tee-union was sheathed with a piece of $0.5 \mathrm{~mm}$ ID PEEK tubing. The PEEK tubing was then connected to the tee-union (i.e., the thread where the $\mathrm{Ag} \mid \mathrm{AgCl}$ wire exits the union) on one end and to the precolumn flow splitter union on the other via 1/16" PEEK LC fittings. Finally, the free thread of the tee-union was used to place a $60 \mathrm{~cm}$ piece of $50 \mu \mathrm{m}$ ID tubing in line with the $\mathrm{Ag} \mid \mathrm{AgCl}$ wire and provide the necessary flow resistance to achieve a splitter:column volumetric split ratio of 10:1.

\section{SI-3. Column Preparation}

Fused silica tubing $(250 \mu \mathrm{m}$ ID) was cut to a length of $25-30 \mathrm{~cm}$ to serve as the capillary EMLC column. A glass fiber/silica composite retaining frit was installed in a separate $\sim 5 \mathrm{~cm}$ piece of $250 \mu \mathrm{m}$ ID tubing based on a previously reported procedure. 1,2 First, $100 \mu \mathrm{L}$ KASIL1 was mixed with $50 \mu \mathrm{L}$ of a freshly prepared solution of aqueous formamide $(25 \% \mathrm{v} / \mathrm{v})$ to form a sol-gel precursor. $2 \mu \mathrm{L}$ of the resulting sol was cast onto a $120 \mu \mathrm{m}$ glass fiber membrane and allowed to wick through the membrane. One end of the fused silica capillary was gently pressed against the wet membrane and twisted to excise a small plug of the wet membrane. The capillaries were then placed in a $95^{\circ} \mathrm{C}$ oven and the sol-gel allowed to cure for $2 \mathrm{~h}$.

After installing the frit, both the column and fritted tubing were connected via a stainless steel union (Restek) with a $250 \mu \mathrm{m}$ diameter thru-hole, as shown in Figure 2. By orienting the two pieces of tubing in this manner, the PGC is intentionally packed into the thru-hole ( $250 \mu \mathrm{m}$ 
diameter) of the union, ensuring conformal contact between the PGC and the steel union. This electrical contact is maintained under the high pressures operative in LC, allowing the union to be used as the working electrode lead without concern of increasing column backpressure or degrading chromatographic efficiency. The columns were slurry packed with $5 \mu \mathrm{m}$ Hypercarb PGC using a procedure derived from reports by Borra et $\mathrm{al}^{1}$ and Deinhammer et al. ${ }^{2}$ A PGC slurry was prepared by first adding $0.12 \mathrm{~g}$ Hypercarb to $4 \mathrm{~mL} \mathrm{10:7} \mathrm{CH}_{2} \mathrm{Br}_{2}$ : $\mathrm{ACN}$ and agitating the resulting solution in a sonicator bath for $15 \mathrm{~min}$. After sonicating, $\sim 0.2 \mathrm{~mL}$ of the slurry was transferred to a threaded stainless steel tube (3 mm ID) which served as the slurry reservoir. The reservoir was connected at one end to the capillary column via a reducing union, and to a slurry packer (Alltech Model 1666) at the other end. The slurry reservoir was immersed in a sonicator bath throughout the column packing procedure. Using acetonitrile as the packing solvent, the pressure was increased to 410 bar over $10 \mathrm{~min}$ and maintained at 410 bar for an additional 10 min. After packing the column, the nitrogen flow to the slurry packer was turned off and the pressure allowed to decrease to atmospheric pressure prior to disconnecting the column.

\section{SI-4. Column Operation}

After the column packing procedure, the column and connecting tubing (i.e., the segment containing the frit) were connected to the LC system and flushed with mobile phase at a backpressure of 120 bar for several hours. The mobile phase was 4\%: ACN and 96\%: $0.10 \mathrm{M}$ $\mathrm{LiClO}_{4}, 0.15 \mathrm{M} \mathrm{LiCl}$. Operational backpressures were typically $\sim 140$ bar, and precise values are provided in the text and/or figure captions. The stationary phase potential was controlled by a $\mathrm{CH}$ Instruments 660B potentiostat (Austin, TX). The reference and counter electrode leads on the potentiostat were hooked to the $\mathrm{Ag} \mid \mathrm{AgCl} \mathrm{PRE}$ via the tungsten connecting wire, and the 
working electrode lead was clamped to the stainless steel union at the column outlet. After applying a potential to the PGC, the background current was allowed to decay to an approximately constant background $(<10 \mathrm{nA}$ change over $10 \mathrm{~min})$ prior to analyte injection. This process generally required $20-30 \mathrm{~min}$, but up to $40 \mathrm{~min}$ was required for the current to stabilize at more extreme potentials (i.e., +400 or $-800 \mathrm{mV} \mathrm{E}_{\text {app }}$ ). The columns were evaluated using a standard mixture of eight aromatic sulfonates (ASFs) dissolved in mobile phase. The concentrations of the ASFs were 4 (NDS), 7.5 (AHBS, BDS, BS, CBS, PTS), or 15 (NTS) $\mu \mathrm{g} / \mathrm{mL}$, resulting in $0.36-1.35 \mathrm{ng}$ injection masses for each analyte.

\section{SI-5. Cyclic Voltammetry}

Cyclic voltammograms (CVs) for AHBS were collected on $3 \mathrm{~mm}$ glassy carbon disk electrodes (CH Instruments; Austin, TX) using a $\mathrm{Ag} \mid \mathrm{AgCl}$ (sat'd $\mathrm{KCl}$ ) reference electrode and platinum coil counter electrode. The electrodes were first polished with successively finer grades of alumina slurry $(5,0.3$, and $0.05 \mu \mathrm{m})$ and subsequently sonicated in methanol to remove adhered alumina. The CVs were measured in a deoxygenated (via sparging with $\mathrm{N}_{2}$ gas for 30 min) solution of $235 \mu \mathrm{M}$ AHBS prepared in mobile phase (i.e., 4\%: $\mathrm{ACN}, 96 \%$ : $0.10 \mathrm{M} \mathrm{LiClO}_{4}$, $0.15 \mathrm{M} \mathrm{LiCl}$ ) over potentials from -0.6 to $+0.4 \mathrm{~V}$ at a scan rate of $100 \mathrm{mV} / \mathrm{s}$.

\section{SI-4. References}

[1]. Ficarro, S. B.; Zhang, Y.; Lu, Y.; Moghimi, A. R.; Askenazi, M.; Hyatt, E.; Smith, E. D.; Boyer, L.; Schlaeger, T. M.; Luckey, C. J.; Marto, J. A., Anal Chem 2009, 81), 3440-3447.

[2] Maiolica, A.; Borsotti, D.; Rappsilber, J., Proteomics 2005, 5, 3847-3850.

[3] Andreolini, F.; Borra, C.; Novotny, M., Anal Chem 1987, 59, 2428-2432.

[4] Deinhammer, R. S.; Ting, E.-Y.; Porter, M. D., Anal Chem 1995, 67, 237-246. 